\title{
EFEKTIFITAS MODIFIKASI BIOFEEDBACK DAN KEGELEXERCISE DENGAN TERAPI YOGA TERHADAP INKONTINENSIA URIN TIPE STRES PADA IBU PERIMENOPAUSE DI KELURAHAN SETIANEGARA KECAMATAN SIANTAR SITALASARI
}

\author{
Tengku Sri Wahyuni \\ Prodi Kebidanan Pematangsiantar \\ Poltekkes Kemenkes Medan
}

\begin{abstract}
Abstrak
Stres inkontinensia merupakan keluarnya urin yang sangat erat hubungannya dengan peningkatan tekanan intra abdominal (bersin,batuk, tertawa, melompat atau gerakan lainnya) yang banyak terjadi pada masa perimenopause. Hal tersebut terjadi akibat perubahan terkait proses penuaan terutama penurunan hormon estrogen. Latihan otot dasar panggul perlu dilakukan untuk menurunkan angka kejadian inkontinensia urin. Tujuan penelitian untuk mengetahui efektifitas modifikasi biofeedbackdan Kegel Exercisedengan terapi Yoga terhadap inkontinensia urin tipe stres pada ibu perimenopause di Kelurahan Setianegara Pematangsiantar.Jenis penelitianquasi eksperimenpre and post test control group design, dengan analisa data yang digunakan uji korelasi Somers'D, dan Kolmogorov Smirnov.Berdasarkan hasil uji statistic diketahui bahwaada hubungan umur dengan inkontinensia urin tipe stres $(\mathrm{p}=0,02)$, tidak terdapat hubungan paritas $(\mathrm{p}=0,78)$, IMT $(\mathrm{p}=0,39)$ dan tidak terdapat perbedaan efektifitas modifikasi biofeedback dan Kegel exercise dengan terapi yoga terhadap inkontinensia urin tipe stres pada wanita perimenopause $(\mathrm{p}=0,068)$. Namun, modifikasi Biofeedback dan Kegel exercise dengan terapi Yoga memberikan perubahan terhadap tingkat inkontinensia urin tipe pada ibu perimenopause. Perlu dilakukan latihan otot dasar panggul sejak usia< 40 tahun untuk mencegah inkontinensia urin.
\end{abstract}

Kata Kunci : Biofeedback, Kegel Exercise, Terapi Yoga, Inkontinensia urin tipe stress, Perimenopause

\section{PENDAHULUAN}

Berdasarkan estimasi penduduk sasaran program kesehatan di Indonesia tahun 2011 penduduk wanita pra usia lanjut (45-59 tahun) cukup tinggi yakni 17.000.769 jiwa (Kemenkes RI, 2012). Usia pada wanita merupakan faktor independen penting yang berhubungan dengan prevalensi inkontinensia urin karena berhubungan dengan ketidakseimbangan hormon terkait menopause. Selain usia, riwayat persalinan pervaginam, Indeks Massa Tubuh (IMT), riwayat histerektomi, infeksi saluran kemih dan trauma perineum juga menjadi faktor predisposisi terjadinya inkontinensia urin (Priceet al, 2010).

Terapi populer untuk mengatasi inkontinensia urin adalah kegel exercise yang bertujuan untuk meningkatkan kekuatan otot dasar panggul. Kegel exercise sangat bermanfaat untuk menguatkan otot- otot disekitar organ reproduksi dan meningkatkan tonus otot lurik uretra dan periuretra sehingga dapat kembali ke fungsi normal (Neumann, dkk, 2006)

Kegel exercise sering dikombinasikan dengan tehnik biofeedback untuk mendapatkan hasil yang lebih baik. Teknik biofeedback dapat merubah suatu kejadian kedalam bentuk signal visual ataupun auditori kemudian signal ini dikembalikan kepada pasien. Dengan teknik biofeedback pasien dapat belajar bagaimana cara memanipulasi dan mengembalikan pada keadaan fisiologis dalam tubuhnya sendiri. Hal ini terbukti dari hasil penelitian yang dilakukan oleh Achirda, dkk (2015) bahwa modifikasi tehnik biofeedback dengan kegel exercise lebih efektif mengatasi inkontinensia urin dengan nilai $\mathrm{p}=0,004$ dibandingkan dengan kegel exercise saja.

Berbagai penelitian terus dilakukan untuk mendapatkan berbagai alternatif pengobatan/ penanganan untuk inkontinensia urin yang tidak hanya efektif, tetapi juga dapat diakses dengan jumlah besar. Salah satu intervensi yang juga memberikan manfaat terapeutik untuk inkontinensia urin adalah yoga. Senam yoga dalam praktiknya melibatkan fisik dan mental yang dirancang untuk meningkatkan kesehatan secara keseluruhan dan kesejahteraan. Hasil penelitian Huang, 2014 mendapatkan bahwa Yoga memberikan efek yang efektif untuk penanganan inkontinensia urin dibandingkan dengan yang tidak dengan nilai $\mathrm{p}=0,004$.

Hasil survey awal berupa wawancara singkat dengan 12 orang ibu perimenopause pada bulan Desember 2016 di Kelurahan Setia Negara didapati 5 orang diantaranya dengan tanda dan gejala inkontinensia urin tipe stres. Hasil suvey tersebut juga menemukan belum pernah ada penelitian tentang inkontinensia dengan intervensi Biofeedback dan Kegel Exercise maupunTerapi Yoga di Kota Pematangsiantar. 


\section{METODE}

Penelitian ini menggunakan jenis penelitian quasi eksperimen, dengan rancangan penelitian pre and post test control group design. Sampel dalam penelitian ini masing-masing 24 orang ibu perimenopause yang memenuhi syarat inklusi dan ekslusi, dan dikelompokkan kedalam kelompok kontrol dan intervensi. Tehnik pengambilan yang digunakan adalah consecutive sampling di Kelurahan Setianegara Kota Pematangsiantar pada Juni-Agustus 2017.

Penelitian ini dilakukan pada 48 responden yang memenuhi kriteria inklusi dan ekslusi yang terdiri dari: Usiaibu $\geq 40$ tahun- 55 tahun, Ibu yang mengalami inkontinensia urine tipe stress, kelemahan otot dasar panggul, Ibu dengan gangguan/ penyakit ginjal dan Ibu dengan prolaps uteri. Responden dibagi menjadi dua kelompok yang mendapat perlakuan senam yoga dan perlakuan biofeedback dan kegel exercise sebanyak $3 \mathrm{x}$ seminggu selama 8 minggu masing- masing 24 responden

\section{HASIL}

\section{Hasil Penelitian}

\section{Tabel 1. Distribusi Frekuensi Karakteristik Responden Penelitian}

\begin{tabular}{|c|c|c|c|c|}
\hline \multirow[t]{3}{*}{ Variabel } & \multicolumn{4}{|c|}{ Perlakuan } \\
\hline & \multicolumn{2}{|c|}{$\begin{array}{c}\text { Modifikasi } \\
\text { biofeedback } \\
\text { \&kegel } \\
\text { exercise }\end{array}$} & \multicolumn{2}{|c|}{ Terapi yoga } \\
\hline & $\mathbf{F}$ & $\%$ & $\mathbf{F}$ & $\%$ \\
\hline \multicolumn{5}{|c|}{ 1. Umur (Tahun) } \\
\hline $40-45$ & 10 & 41,7 & 0 & 0 \\
\hline $46-50$ & 6 & 25,0 & 7 & 29,2 \\
\hline $51-60$ & 8 & 33,3 & 17 & 70,8 \\
\hline \multicolumn{5}{|l|}{ 2. $\quad$ Paritas } \\
\hline $1-2$ & 4 & 16,7 & 6 & 25,0 \\
\hline $3-4$ & 16 & 66,7 & 14 & 62,5 \\
\hline $5-6$ & 4 & 16,7 & 4 & 16,7 \\
\hline \multicolumn{5}{|c|}{ 3. Pendidikan } \\
\hline Tidak Lulus SD & 3 & 12,5 & 1 & 4,2 \\
\hline SD & 8 & 33,3 & 13 & 12,5 \\
\hline SMP & 5 & 20,8 & 5 & 20,8 \\
\hline SMA & 8 & 33,3 & 12 & 50,0 \\
\hline PT & 0 & 0 & 3 & 12,5 \\
\hline \multicolumn{5}{|c|}{ 4. Indeks Masa Tubuh } \\
\hline$<18.50$ & 0 & 0 & 1 & 4,2 \\
\hline $18.50-24.99$ & 13 & 54,2 & 11 & 45,8 \\
\hline $25.00-29.99$ & 11 & 45,8 & 10 & 41,7 \\
\hline$\geq 30,00$ & 0 & 0 & 2 & 8,3 \\
\hline \multicolumn{5}{|c|}{ Riwayat Kontrasepsi } \\
\hline Tidak pernah & 7 & 29,2 & 10 & 41,7 \\
\hline Kondom & 1 & 4,2 & 0 & 0 \\
\hline Pil & 5 & 20,8 & 3 & 12,5 \\
\hline Suntik & 11 & 45,8 & 7 & 29,2 \\
\hline IUD & 0 & 0 & 2 & 8,3 \\
\hline MOW & 0 & 0 & 2 & 8,3 \\
\hline \multicolumn{5}{|c|}{ Riwayat Persalinan } \\
\hline Abortus & 1 & 4,2 & 1 & 4,2 \\
\hline Normal & 22 & 91,8 & 21 & 87,5 \\
\hline Seksio sesar & 1 & 4,2 & 2 & 8,3 \\
\hline
\end{tabular}

\begin{tabular}{|l|c|c|c|c|}
\hline \multicolumn{5}{|l|}{ Inkontinensia Urin Tipe Stres } \\
\hline Ringan & 0 & 0 & 16 & 66,7 \\
\hline Sedang & 7 & 29,2 & 8 & 33,3 \\
\hline Berat & 17 & 70,8 & 0 & 0 \\
\hline
\end{tabular}

Berdasarkan hasil tabel 1 diketahui responden pada kelompok biofeedback dan kegel exercise mayoritas adalah berumur 40 - 45 tahun sebanyak $41,7 \%$ dan minoritas umur 46 - 50 tahun $(25,0 \%)$, sedangkan Pada kelompok terapi yoga, mayoritas responden berumur 51 55 tahun (70,8\%). Paritas responden pada kelompok biofeedback dan Kegel exercise mayoritas adalah paritas 3 - $4(66,7 \%)$, sementara pada kelompok terapi yoga, mayoritas paritas responden adalah $3-4$ (58,3\%) dan minoritas pada paritas $5-6(16,7 \%)$. Pendidikan responden pada kelompok biofeedback dan Kegel exercise mayoritas adalah SD dan SMA masing-masing 33,3\%, namun demikian ada $12,5 \%$ responden yang tidak lulus $\mathrm{SD}$, sedangkan pada kelompok terapi yoga diketahui mayoritas pendidikan responden adalah SMA $(50,0 \%)$ dan didapati 4,2\% responden yang tidak lulus SD. Indeks masa tubuh (IMT) diketahui mayoritas responden pada kelompok biofeedback dan Kegel exercisemayoritas berada pada kisaran IMT 18,50 - 24,99 kg/m² (kategori normal) sebanyak $54,2 \%$, sedangkan pada kelompok terapi yoga, mayoritas IMT berada pada kisaran 18,50 - 24,99 kg/m ${ }^{2}$ (kategori normal) yaitu 45,8\% dan minoritas berada pada IMT $<18,50 \mathrm{~kg} / \mathrm{m}^{2}$ yaitu $4,2 \%$. Inkontinensia urin tipe stres pada responden yang mengikuti biofeedback dan kegel exercise, mayoritas ditemukan dengan kategori berat sebanyak $70,8 \%$, sementara itu kejadian inkontinensia urin tipe stress pada respondenyang mengikuti terapi yoga.

Berdasarkan hasil pada tabel 2 diketahui inkontinensia urin tipe stres kategori ringan dan sedang, banyak dialami oleh responden berumur 51 - 55 tahun, masing-masing 75,0\% dan 60,0\%. Inkontinensia urin tipe stres kategori berat justru banyak ditemukan pada kelompok umur $40-45$ tahun. Hasil analisis menunjukkan $\mathrm{p}=0,02(\mathrm{p}<0,05)$, yang berarti bahwa ada hubungan umur dengan kejadian inkontinensia urin

Berdasarkan hasil pada tabel 2 diketahui inkontinensia urin tipe stres kategori ringan dan sedang, banyak dialami oleh responden berumur 51 - 55 tahun, masing-masing 75,0\% dan 60,0\%. Inkontinensia urin tipe stres kategori berat justru banyak ditemukan pada kelompok umur $40-45$ tahun. Hasil analisis menunjukkan $\mathrm{p}=0,02(\mathrm{p}<0,05)$, yang berarti bahwa ada hubungan umur dengan kejadian inkontinensia urin tipe stress.

Tabel 2 menunjukkan bahwa paritas $3-4$ paling banyak mengalami inkontinensia urin tipe stres pada semua kategori, masing-masing kategori ringan $(56,2 \%)$, sedang $(73,3 \%)$ dan berat $(58,8 \%)$. Hasil analisis menunjukkan $\mathrm{p}=0,78(\mathrm{p}>0,05)$, yang berarti tidak ada hubungan paritas dengan kejadian inkontinensia urin tipe stres pada penelitian ini,

Tabel 2 juga menginformasikan bahwa inkontinensia urin tipe stres kategori ringan dan sedang banyak dialami oleh responden dengan IMT 18,50 $24,99 \mathrm{~kg} / \mathrm{m}^{2}$ dan $25,00-29,99 \mathrm{~kg} / \mathrm{m}^{2}$, masing-masing $43,8 \%$ dan $46,7 \%$. Inkontinensia urin tipe stres kategori berat paling banyak dialami oleh kelompok IMT 18,50 - 
$24,99 \mathrm{~kg} / \mathrm{m}^{2}$ yaitu $58,8 \%$. Berdasarkan uji statistik diperoleh hasil $\mathrm{p}=0,39(\mathrm{p}>0,05)$, yang berarti tidak ada hubungan IMT dengan kejadian inkontinensia urin pada penelitian ini.

Tabel 3. Perbedaan Efektifitas Modifikasi Biofeedbackdan Kegel Exercise dengan Terapi Yoga Terhadap Inkontinensia Urin Tipe StresSetelah Intervensi

\begin{tabular}{|c|c|c|c|c|c|c|c|}
\hline \multirow[t]{3}{*}{ Kelompok } & \multicolumn{6}{|c|}{ Inkontinensia Urin Tipe Stress } & \multirow[b]{2}{*}{$\mathbf{p}^{*}$} \\
\hline & \multicolumn{2}{|c|}{$\begin{array}{c}\text { Tidak } \\
\text { Inkontinensia } \\
\text { urine } \\
\end{array}$} & \multicolumn{2}{|c|}{ Sedang } & \multicolumn{2}{|c|}{ Berat } & \\
\hline & $\mathbf{F}$ & $\%$ & $\mathbf{F}$ & $\%$ & $\mathbf{F}$ & $\%$ & \\
\hline $\begin{array}{c}\text { Modifikasi } \\
\text { Biofeedback } \\
\text { \& Kegel } \\
\text { Exercise }\end{array}$ & 5 & 26,3 & 13 & 56,5 & 6 & 100 & 0,068 \\
\hline Terapi Yoga & 14 & 73,7 & 10 & 43,5 & 0 & 0 & \\
\hline
\end{tabular}

Berdasarkan tabel 3 diperoleh hasil $\mathrm{p}=0,068$, yang berarti bahwa tidakterdapat perbedaan modifikasi biofeedbackdan kegel exercise dengan terapi yoga terhadap inkontinensia urin tipe stress. Walaupun secara statistik tidak terdapat perbedaan antara keduanya namun dapat dilihat keberhasilannya mengurangi tingkatan inkontinensia urin tipe stres berdasarkan derajatnya.

Tabel 4.Distribusi Frekuensi Inkontinensia Urin Tipe Stres Sebelum dan Sesudah Terapi Yoga

\begin{tabular}{|c|c|c|c|c|c|c|c|c|}
\hline \multirow{3}{*}{$\begin{array}{c}\text { Inkontine } \\
\text { nsia urin } \\
\text { tipe stres } \\
\text { sebelum } \\
\text { Yoga }\end{array}$} & \multicolumn{6}{|c|}{ Inkontinensia urin tipe stres sesudah Yoga } & \multicolumn{2}{|c|}{ Total } \\
\hline & \multicolumn{2}{|c|}{$\begin{array}{c}\text { Tidak } \\
\text { inkontinensi } \\
\text { a urin }\end{array}$} & \multicolumn{2}{|c|}{ Ringan } & \multicolumn{2}{|c|}{ Sedang } & \multirow[t]{2}{*}{$\mathrm{F}$} & \multirow[t]{2}{*}{$\%$} \\
\hline & $\mathrm{f}$ & $\%$ & $\mathrm{f}$ & $\%$ & $\mathrm{f}$ & $\%$ & & \\
\hline Ringan & 4 & 25,0 & 12 & 75,0 & 0 & 0 & 16 & 100 \\
\hline Sedang & 1 & 12,5 & 1 & 12,5 & 6 & 75,0 & 8 & 100 \\
\hline Total & 5 & 20,8 & 13 & 54,2 & 6 & 25,0 & 24 & 100 \\
\hline
\end{tabular}

Berdasarkan tabel 4 menunjukkan bahwa terapi Yoga mampu memberikan perubahan terhadap tingkat inkontinensia urin tipe stres. Dari 16 responden yang mengalami inkontinensia urin tipe stres kategori ringan, setelah dilakukan terapi yoga menjadi 4 responden $(25,0 \%)$ tidak mengalami inkontinensia urin. Dari 8 responden yang mengalami inkontinensia urin tipe stres kategori sedang menjadi 1 responden $(12,5 \%)$ yang mengalami inkontinensia urin tipe stres kategori ringan dan tidak inkontinensia urin.

Tabel 5. Distribusi Frekuensi Inkontinensia Urin Tipe Stres Sebelum dan Sesudah Biofeedback dan Kegel Exercise

\begin{tabular}{|c|c|c|c|c|c|c|}
\hline $\begin{array}{c}\text { Inkontinensia } \\
\text { urin tipe stres } \\
\text { sebelum } \\
\text { modifikasi } \\
\text { biofeedback + } \\
\text { biofeedback dan } \\
\text { Kegel exercise }\end{array}$ & $\begin{array}{c}|c| \\
\text { Inkontinensia urin tipe stres sesudah } \\
\text { modifikasi biofeedback } \\
\text { biofeedback dan Kegel exercise }\end{array}$ & \multicolumn{3}{|c|}{ Total } \\
\cline { 2 - 5 } & $\begin{array}{c}\text { Tidak } \\
\text { inkontinensia urin }\end{array}$ & \multicolumn{2}{|c|}{ Ringan } & & \\
\hline Sedang & 7 & 100 & 0 & 0 & 7 & 100 \\
\hline Berat & 7 & 41,2 & 10 & 58,8 & 17 & 100 \\
\hline Total & 14 & 58,3 & 10 & 41,7 & 24 & 100 \\
\hline
\end{tabular}

Berdasarkan tabel 5 menunjukkan bahwa modifikasi biofeedback dan Kegel exercise juga memberikan perubahan terhadap tingkat inkontinensia urin tipe stres. Dari 7 responden yang mengalami inkontinensia urin tipe stres kategori sedang, seluruhnya (100\%) menjadi tidak inkontinensia urin setelah mengikuti Biofeedback dan Kegel exercise. Dari 17 responden yang mengalami inkontinensia urin tipe stres kategori berat, menjadi 7 responden $(41,2 \%)$ tidak inkontinensia urin dan 10 responden $(58,8 \%)$ menjadi inkontinensia urin tipe sedang.

\section{PEMBAHASAN}

Pada penelitian ini ditemukan hubungan faktor umur dengan inkontinensia urin tipe stres $(p=0,02)$. Kejadian inkontinensia urin biasanya dikaitkan dengan proses menua. Proses ini merupakan proses alami yang disertai dengan penurunan kondisi fisik, salah satunya penurunan fungsi pada sistem perkemihan.

Wiratmoko (2003) menemukan bahwa inkontinensia urin banyak ditemukan pada usia yang lebih muda (50-54 tahun) walaupun secara statistik tidak bermakna. Hasil berbeda dilaporkan oleh Shakhatreh (2005) di Jordan yang meneliti kejadian inkontinensia urin pada wanita umur 50-65 tahun. Ia menemukan tidak ada hubungan umur dengan kejadian inkontinensia urin tipe stres.

Stres inkontinensia urin lebih banyak ditemukan pada multiparitas dibandingkan nulliparitas. Efek persalinan. Pada penelitian ini tidak ditemukan hubungan paritas dengan inkontinensia urin tipe stres $(\mathrm{p}=0,78)$. Hasil penelitian yang sama juga dilaporkan oleh Shakhatreh (2005) di Jordan yang menemukan tidak ada hubungan paritas dengan inkontinensia urin tipe stres. Ketiadaan hubungan pada penelitian ini mungkin disebabkan oleh trend yang tidak spesifik berkaitan dengan kejadian inkontinensia urin tipe stres dimana pada paritas 1-2 ditemukan $20,8 \%$, paritas 3-4 sebanyak $62,5 \%$ dan paritas 5-6 sebesar $16,7 \%$.

Peningkatan IMT adalah salah satu faktor risiko inkontinensia urin tipe stres. Secara teoritis dinyatakan bahwa peningkatan tekanan intra abdominal bersamaan dengan penambahan IMT mengakibatkan peningkatan tekanan intravesikel yang lebih tinggi secara proporsional sehingga melebihi tekanan penutupan uretra dan mengacu pada inkontinensia (Magonet al, 2011). Berdasarkan uji statistik diketahui tidak ada hubungan IMT dengan kejadian inkontinensia urin tipe stres $(\mathrm{p}=0,39)$ pada penelitian ini. Shakhatreh (2005) juga menemukan tidak ada hubungan inkontinensia urin tipe stres dengan IMT. Pada penelitian ini 50\% responden berada pada ketegori IMT normal.

Berbagai cara telah dilakukan untuk mengatasi inkontinensia urin. Secara umum penatalaksanaannya adalah pemakaian peralatan yang menekan keluarnya urin, pengobatan/medikamentosa, operasi dan latihan penguatan otot dasar panggul (Suparman \& Rompas, 2008; Magon et al, 2017). Latihan penguatan otot dasar panggul pertama kali diperkenalkan oleh Dr. Arnold Kegel tahun 1940 untuk mengatasi inkontinensia urin tipe stres 
(Rahajeng, 2010). Selain itu juga diperkenalkan Yoga untuk mengatasi keluhan inkontinensia urin (Huang et al, 2014). Pada penelitian ini tidak ditemukan perbedaan efektifitas modifikasi biofeedback dan Kegel exercise dengan Yoga untuk mengatasi inkontinensia urin tipe stres ( $\mathrm{p}=0,068)$. Hal ini berarti modifikasi biofeedback dan Kegel exercise dengan Yoga sama-sama mampu mengatasi inkontinensia urin tipe stres.

Namun, pada penelitian ini terapi yoga mampu memberikan perubahan terhadap tingkat inkontinensia urin tipe stres. Dari 16 responden yang mengalami inkontinensia urin tipe stres kategori ringan, setelah dilakukan terapi Yoga menjadi 4 responden $(25,0 \%)$ tidak mengalami inkontinensia urin. Dari 8 responden yang mengalami inkontinensia urin tipe stres kategori sedang menjadi 1 responden $(12,5 \%)$ yang mengalami inkontinensia urin tipe stres kategori ringan dan tidak inkontinensia urin. Modifikasi biofeedback dan Kegel exercise juga memberikan perubahan terhadap tingkat inkontinensia urin tipe stres. Dari 7 responden yang mengalami inkontinensia urin tipe stres kategori sedang, seluruhnya $(100 \%)$ menjadi tidak inkontinensia urin setelah mengikuti Biofeedback dan Kegel exercise. Dari 17 responden yang mengalami inkontinensia urin tipe stres kategori berat, menjadi 7 responden $(41,2 \%)$ tidak inkontinensia urin dan 10 responden $(58,8 \%)$ menjadi inkontinensia urin tipe sedang.

Senam Kegel merupakan salah satu terapi non farmakologis untuk mengatasi inkontinensia urin bila dilakukan secara rutin. Senam ini dilakukan untuk membangun kembali kekuatan otot dasar panggul serta untuk mencapai 40-60 kali pengurangan terjadinya inkontinensia urin, dilakukan selama 10 detik setiap harinya dengan melakukan minimal 10 kali latihan. Peningkatan dapat dilihat dalam waktu 4-6 minggu dengan peningkatan maksimal selama 3 bulan (Stanley \& Beare, 2006). Senam ini melibatkan kontraksi berulang otot pubokoksigeus, otot yang membentuk struktur pengokong panggul dan mengelilingi pintu panggul pada vagina, eretra dan rectum (Stanley \&Beare, 2006). Mekanisme terjadinya peningkatan kekuatan otot dasar panggul dimulai dari meningkatnya resistensi uretra melalui kontraksi aktif otot pubokoksigeus. Kemudian kontraksi ini akan menambah kekuatan penutupan uretra dan meningkatkan sokongan pada struktur panggul dan periuretra, sehingga otot-otot dasar panggul yang tidak tampak dari luar dapat diaktifkan secara langsung dan benar (Achirda dkk, 2015).

Salah satu gerakan Yoga yang berhubungan dengan kekuatan otot dasar panggul adalah Bhuyanggasana. Gerakan ini dilakukan dengan telungkup, melemaskan otot dan menenangkan hati, meletakkan telapak tangan di lantai, di bawah bahu dan siku, tubuh dan pusar sampai jari-jari kaki tetap di lantai, angkat kepala dan tubuh ke atas perlahan seperti kobra ke atas, bengkokkan tulang punggung ke atas (Patil et al, 2012)

Gerakan Yoga ini ditekankan untuk melatih kesadaran stuktur dasar panggul dan meningkatkan kontrol seluruh otot-otot dasar panggul, meningkatkan kebugaran secara umum dan mengondisikan serta meningkatkan kesadaran diri penuh, pernafasan dalam dan relaksasi
(Huang et al, 2014). Yoga sebagai alternatif inkontinensia urin dapat dilakukan pada usia pertengahan (45-59 tahun) dan usia lanjut (60-74 tahun) tanpa komplikasi riwayat urologi, aman, fisibel dan efikasi(Huang et al, 2014).

\section{Kesimpulan}

1. Modifikasi biofeedback dan Kegel exercise efektif untuk mengatasi inkontinensia urin tipe stres pada ibu perimenopause

2. Terapi yoga efektif untuk mengatasi inkontinensia urin tipe stres pada ibu perimenopause

3. Tidak terdapat perbedaan efektifitas modifikasi biofeedback dan Kegel exercisedengan terapi Yoga untuk mengatasi inkontinensia urin tipe stres pada ibu perimenopause $(\mathrm{p}=0,068)$

\section{Saran}

Perlu dilakukan pencegahan inkontinensia urin tipe stres dengan berbagai latihan sejak usia $<40$ tahun.

Diharapkan penelitian ini ditindaklanjuti oleh petugas kesehatan dalam bentuk kegiatan pengabdian masyarakat sehingga lebih banyak yang dapat merasakan manfaatnya

Penelitian lanjutan perlu dikembangkan dengan jumlah sampel yang lebih besar, waktu evaluasi yang lebih lama serta instruktur yang mengajarkan senam kegel maupun yoga, sebaiknya tidak hanya sebagai parktisi tapi juga punya keilmuan dibidang tersebut.

\section{DAFTAR PUSTAKA}

Achirda, N., Jawi, M., \& Sugijanto. (2015). Kombinasi Biofeedback dan Kegel Exercise Lebih Meningkatkan Kekuatan Otot Dasar Panggul pada Inkontinensia Urinae Tipe Stres Pasca Partus Normal. Jakarta .

Bo, K., \& Herbert, D. R. (2013). There is not yet stong evidence that exercise regimens other than pelvic muscle training can reduce stress urinary incontinence in women; a systematic review. Journal of Physiotheraphy, 59, 159-168.

Dahlan, M. (2011). Statistik Untuk Kedokteran dan Kesehatan Masyarakat. Jakarta: Salemba Medika.

Daneshgari, F., \& Moore, C. (2007). Pathophysiology of stress urinary incontinence in women. Multidisciplinary Management of Female Pelvic Floor Disease , 45-50.

Huang, A. J., Jenny, H. E., Chesney, M. A., Schembri, M., \& Subak, L. L. (2014). A Group-Based Yoga Theraphy Intervention for Urinary Incontinence in Women: A Pilot Randomized Trial. Female Pelvic Med Reconstr Surg, 20 (3), 147-154.

Madiyono, B., Mz Moeslichan, S., Sastroasmoro, S., Budiman, I., \& Purwanto, S. (2011). Perkiraan Besar Sampel . Dalam S. Sastroasmoro, \& S. Ismael, Dasar-Dasar Metodologi Penelitian Klinis (hal. 348-382). Jakarta: Sagung Seto. 
Magon, N., Kalra, B., Malik, S., \& Chauchan, M. (2011). Stress urinary incontinence: What, when, why, and then what? Journal of Mid-life Health, 2 (2), 57-64.

Milne, J., \& Moore, K. (2006). Factors impacting selfcare for urinary incontinence. Urologic Nursing, $26,41-51$.

Morkved, S., Bo, K., \& Fjortoft, T. (2002). Effect of adding biofeedback to pelvic floor muscle training to treat urodynamics stress incontinence. Obstet Gynecol, 730-739.

Nygaard, I. (2004). Stress Urinary Incontinence. Obstet Gynecol, 104, 607-620.

Patil, N., Nagaratna, R., \& Garner, C. (2012). Effect of integrated Yoga on neurogenic bladder dysfunction in patients with multiple sclerosis A prospsective observational case series. Complementary Therapies in Medcine, 20 (6), 424-430.

Rahajeng. (2010). Efek Latihan Kegel pada Kekuatan Otot Dasar Panggul Ibu Pasca Persalinan. Jurnal Kedokteran Brawijaya, 26 (2), 120-123.

Sastroasmoro, S. (2011). Pemilihan Subjek Penelitian. Dalam S. Sastroasmoro, \& S. Ismael, DasarDasar Metodologi Penelitian Klinis (hal. 88103). Jakarta: Sagung Seto.

Shakhatreh, F. M. (2005). Epidemiology of urinary incontinence in Jordanian women. Saudi Med J, 26 (5), 830-835.
Stanley, M., \& Beare, P. (2006). Buku Ajar Keperawatan Gerontik. Jakarta: EGC.

Suparman, E., \& Rompas, J. (2008). Inkontiinensia urin pada perempuan menopause. Maj Obstet Ginekol Indones, 32 (1), 48-54.

Tendean, H. M. (2007). Deteksi Inkontinensia Urin pada Usia Post Menopause dengan Menggunakan Kuesioner IIQ-7 dan UDI-6. $J K M, 6$ (2).

Wiratmoko, A. (2003). Pola Inkontinensia Urin Pada Wanita Usia Di Atas Lima Puluh Tahun. Tesis, Fakultas Kedokteran Universitas Diponegoro, Program Pendidikan Dokter Spesialis I Obstetri dan Ginekologi, Semarang .

Wyman, J. (2003). Treatment of Urinary Incontinence in Men and Older Women. A.J.N, 103 (3), 2635 . 